\title{
KONSEP KAFIR DALAM PANDANGAN NAHDLATUL ULAMA (NU) DAN FORUM UMAT ISLAM (FUI) SUMATERA UTARA
}

\author{
Fitriani dan Siti Aisyah \\ Universitas Islam Negeri Sumatera Utara (UINSU) Medan \\ rianinaser@gmail.com
}

\begin{abstract}
Abstrak
Kafir merupakan istilah yang tak indah didengar. Namun upaya Nahdlatul Ulama mengubahnya menjadi istilah non-Muslim mendapat respon penolakan dari berbagai pihak seperti Forum Umat Islam. Penelitian ini berupaya mengkaji konsep kafir menurut Nahdlatul Ulama dan Forum Umat Islam Sumatera Utara. Penelitian ini merupakan field research, dengan metode kualitatif danbersifat deskriptif analitikserta Comparative Approach. Nahdlatul Ulama Sumut menyatakan mereka sepakat dengan rekomendasi istilah non-muslim, karena tidak mencapai status kafir sebagaimana di dalam kitab fikih. Sementara Forum Umat Islam menyatakan tidak setuju dengan Nahdlatul Ulama dan menyatakan semua non islam adalah kafir.
\end{abstract}

Kata kunci : Forum Umat Islam, Kafir, Nadhlatul Ulama

\section{Abstrak}

Kafir is a term that is not beautiful to hear. But the efforts of Nabdlatul Ulama to convert it to nonMuslim terms have been rejected by various parties like the Forum Umat Islam. This study seeks to examine the concept of infidelity according to the Nabdlatul Ulama and Forum Umat Islam North Sumatra. This research is a field of research, with qualitative and analytic descriptive methods and Comparative Approach. The North Sumatra Nabdlatul Ulama said they agreed with the recommendation of the term non-Muslim, because it does not reach the status of infidel as in the book of figh. While the Forum Umat Islam stated that it disagreed with the Nabdlatul Ulama and declared all non-Muslims to be Kafir.

Keyword : Islamic Community Forum (FUI), Infidel, Nadhlatul Ulama

\section{Pendahuluan}

Islam merupakan agama terbesar, penyempurna agama-agama sebelumnya,dan Islam adalah rahmat, sertaislam merupakan manifestasi dari sifat rahman dan rahim Allah (Jirhanuddin, 2010 : 139).Akidah merupakan sesuatu yang amat penting dalam islam diyakini oleh kalbu (wijdan) dan diterima oleh akal, sehinggamenjadi pembenaran (keyakinan) yang bulat, sesuai dengan realitas (yang diimani), dan bersumber dari dalil (Hafidz, 2015 : 126).Akan tetapi tak sedikit manusia yang tidak meyakini Islam (tidak memeluk agama Islam), dan ia dinyatakan seorang kafir secara pasti (Syamsuddin, 2010 : 108). 
Kafir berarti menyembunyikan atau menutupi. Bahasa Inggris, kata kufur hampir senada dengan kata cover yang artinya juga 'menutup'(Nafi, 2018 : 125). Sikap dan perbuatan kafir sangat menyalahi tauhid, maka orang dipandang sebagai seburuk-buruk makhluk yang kelak akan masuk neraka (Hads, 2018 : 164).

Dewasa ini, istilah kafir telah menjadi perbincangan yang banyak dibahas dan diperdebatkan oleh beberapa kelompok kaum Muslimin Indnesia, hal ini bermula dari pernyataan ketua umum Pengurus Besar Nahdlatul Ulama (PBNU) Said Aqil Siraj saat membacakan hasil musyawarah pada acara Musyawarah Nasional Alim Ulama dan Konferensi Besar Nahdlatul Ulama(Munas dan Konbes NU) di Pondok Pesantren Miftahul Huda Al Azhar, Citangkolo, Banjar, Jawa Barat, menyatakan bahwa istilah kafir tidak dikenal dalam sistem kewarganegaraan pada suatu negara dan bangsa. Setiap warga negara memiliki hak yang sama dimata konstitusi. Karena itu yang ada adalah non-Muslim, bukan kafir. Begitu halnya saat Rasul di Madinah, tak ada istilah kafir, melainkan non muslim.

Hal ini menimbulkan polemik, banyak yang setuju, namun ada juga kelompok yang menunjukkan sikap tidak sepakat dengan putusan itu. Diantaranya Forum Umat Islam(FUI) yang menilai bahwa rekomendasi tersebut dinilai hoax.

Berdasarkan permasalahan diatas, penulis berupaya mengkaji dasar NU mengganti kata kafir menjadi non-Muslim dan alasan FUI sebegitu tidak menyetujuinya, serta bagaimana kafir dalam pandanganNU dan Kafir dalam pandangan FUI. Namun dalam hal ini pandangan mengenai kafir tersebut hanya difokuskan NU dan FUI WilayahSumatera Utara.

\section{Metodologi Penelitian}

Metode penelitian merupakan salah satu komponen yang mempengaruhi berhasilnya sebuah tulisan yang akan dicapai (Nazir, 2005 : 44).Penelitian ini merupakan penelitian lapangan (field research), dengan metode kualitatif untuk mengetahui makna yang tersembunyi dari gejala yang ada (Noor, 2002 : 168), danbersifat deskriptif analitik, yaitu dengan mendeskripsikan, mencatat, dan menganalisis fenomena yang ada, berkenaan dengan kondisi atau hubunganyang ada dalam objek penelitian (Mardalis, 2008 : 26),serta pendekatan perbandingan (Comparative Approach), membandingkan berbagai pendapat yang ada dalam ilmu tersebut, sehingga dapat diketahui persamaan dan perbedaannya (Nata, 2016 : 190). Dalam hal menganalisis pandangan NUdan FUI Sumut.

\section{Pengertian KafirMenurut NU}

Berdasarkan Dokumen Pokok-Pokok Pikrian PWNU SU, kafir dari segi bahasa mengandung arti: menutupi. Malam disebut "kafir", karena ia menutupi siang atau menutupi 
benda-benda dengan kegelapannya. Awan juga disebut "kafir" karena ia menutupi matahari. Demikian pula petani yang terkadang juga disebut "kafir" karena ia menutupi benih dengan tanah. Secara istilah, para ulama tidak sepakat dalam menetapkan batasan kafir sebagaimana berbeda pendapat dengan batasan iman. Kalau iman diartikan "pembenaran" (al-tasdiq) terhadap Rasulullah Saw berikut ajaran-ajaran yang dibawanya, maka kafir diartikan dengan "pendustaan" (al-takdbib) terhadap ajaran-ajaran beliau. Inilah batasan yang paling umum dan sering terpakai dalam buku-buku akidah. Jadi, orang kafir ialah orang yang mengingkari ajaran Islam yang seharusnya dia imani.

Abror Dawud Faza menyatakan NU dalam hal ini masih sama dengan pengertian kafir pada umumnya bahwa kafir adalah selain orang Muslim. Kafir berasal dari bahasa arab كافرyang berarti menutup diri dari kebenaran.

Hadratus Syaikh KH. Hasyim Asy'ari, mengutip Imam Qadhi Iyadh bahwa yang termasuk kelompok kafir adalah: beribadah kepada selain Allah, kelompok Dahriyah, Nasrani, Yahudi, Majusi, penyembah berhala, penyembah malaikat, penyembah setan, matahari dan bintang. Semuanya adalah kufur secara jelas dan atas kesepakatan semua kaum Muslimin (T.t, : 19).

Didalam al-Qur'an kata kafir disebutkan sebanyak 525 kali dan mengacu kepada perbuatan manusia yang berhubungan dengan Tuhan. Kafir merupakan istilah untuk mereka yang menolak kebenaran Islam, dan istilah tersebut telah dicantumkan di dalam alQur'an,umat Islam yakin bahwa al-Qur'an adalah Kalamullah yang tidak ada keraguan padanya sehingga NUtidak mungkin mengubah kata yang memang sudah Allah tetapkan di dalam alQur'an. Hanya saja apabila berkaitan dengan urusan kenegaraan/Negara, maka istilah kafir diganti dengan menggunakan sebutan non-Muslim.

\section{Jenis- Jenis Kafir}

Nahdlatul Ulama (NU) mengungkapkan bahwa Ada 4 jenis kafir yang disebutkan di dalam kitab fiqih, diantaranya (Abror, 2019):

\section{KâfirHarbi(كافر هربي)}

Kâfir harbi adalah orang kafir yang wajib diperangi sebab mereka adalah kafir yang memusuhi Islam. Mereka senantiasa ingin memecah-belah orang mukmin dan bekerjasama dengan orang yang telah memerangi Allah SWT dan Rasul-Nya sejak dahulu. Hal ini disebabkan oleh sifat khas mereka yang selalu membuat kerusuhan di muka bumi ini, terutama pelanggaran yang paling serius terhadap kemahaagungan dan kemahasempurnaan Tuhan (Nina, $2005: 37$ ).

\section{Kâfir Mu'ahad(كافر معاهد)}


KâfirMu'ahad adalah orang kafir yang dilindungi karena mengikat perjanjian dengan Negara Islam.kâfir Mu'ahad sebenarnya tidak jauh berbeda dengan kâfirharbi karena kâfirmu'ahad juga berasal dari Dârul Harbi, hanya saja mereka telah mengikat perjanjian damai dengan Negara Islam. Oleh sebab itu, hak dan kewajiban mereka harus dilindungi.

3. Kâfir Musta'min(كافر مستاءمن)

Kâfir Musta'min adalah orang kafir yang datang dari suatu negara ke Negara Islam untuk meminta perlindungan. Pada dasarnya mereka sama dengan kâfir mu'ahad dan kâfir dřimmi sehingga hak dan kewajiban mereka harus dilindungi didalam Negara Islam.

4. Kâfir Drimmi( كافر ذمي)

Kâfir Də̧immi adalah kafir yang berdamai dengan orang-orang Islam, mereka tinggal di Negara Islam dan memiliki hak dan kewajiban yang sama dengan agama lain dalam urusan kenegaraan. Mereka tidak mengancam dan membahayakan akidah umat Islam sehingga mereka dapat hidup aman dalam wilayah kekuasaan Islam, hanya saja mereka harus membayar pajak atau jisyab kepada pemerintahan Islam tersebut.

\section{Dasar Penggantian Istilah Kafir Menjadi Non-Muslim}

Nahdlatul Ulama (NU) telah selesai menyelenggarakan Musyawarah Nasional Alim Ulama dan Konferensi Besar Nahdlatul Ulama (Munas Alim Ulama dan Konbes NU) di Pondok Pesantren Miftahul Huda Al-Azhar Citangkola kota Banjar, Jawa Barat pada tanggal 27 Februari hingga 1 Maret 2019. Adapun pembahasan penting yang dibahas dalam forum tersebut terkait problem masyarakat, bangsa, dan negara.

Munas Alim Ulama dan Konbes NU merupakan forum tertinggi kedua setelah Muktamar NU yang merupakan sebuah pertemuan atau permusyawaratan tertinggi diadakan oleh pimpinan pusat NU, pertemuan tersebut dihadiri oleh perwakilan seluruh pengurus NUse-Indonesia. Mukatamar NUdiadakan untuk mengambil keputusan bersama mengenai suatu permasalahan yang sedang dihadapi bersama di dalam organisasi tersebut.

Munas Alim Ulama yang diselenggarakan di Jawa Barat dihadiri oleh seluruh Syuriah dan Tanfiziah se-Indonesia yang mewakili tiap-tiap provinsi dari 34 provinsi di Indonesia. Pertemuan ini membahas mengenai problem-problem aktual dari sisi hukum Islam atau fiqih melalui forum Bahtsul Masâil.

Bahtshul masâil adalah sebuah forum untuk membahas kajian-kajian keagamaan. Ada 3 pembahasan yang dibahas dalam sidang Bahtsul masâil pada pertemuan tersebut, yaitu pertama, Komisi Babtsul Masâil ad-Diniyah al-Wadi'yyyab; forum ini membahas tentang bahaya sampah plastik, perusahaan AMDK (Air Minum Dalam Kemasan) yang menyebabkan sumur warga kering, kemudian masalah money game dan legalitas syariat bagi peran pemerintah. Kedua, 
Komisi Bahtsul Masail ad-Diniyah al-Maudlu'iyyab; dalam forum ini membahas mengenai negara, kewarganegaraan dan hukum negara serta konsepsi Islam Nusantara, dan pembahasan istilah kafir berada pada komisi ini. Ketiga, Komisi Bahtsul Masâil ad-Diniyah al-Qanuniyah; di forum ini membahas tentang Rancangan Undang-Undang (RUU) anti monopoli dan persaingan usaha serta Rancangan Undang-Undang (RUU) penghapusan kekerasan seksual.

NUmenganjurkan agar kata kafir tidak digunakan untuk melabeli non-Muslim dalam ranah sosial dan kehidupan berbangsa dan bernegara, sebab istilah kafirtidak dikenal dalam sistem kewarganegaraan pada suatu negara dan bangsa. NUmengintroduksi termmuwâthinun, atau warga negara. Dalam perspektif itu setiap warga negara memiliki hak yang sama di mata konstitusi.

Menurut Abror tata kafir digunakan didalam agama dalam pembahasan internal kita, tidak ada orang lain disitu. Kalo ada orang lain duduk disitu masak kita bilang, 'hai kafir', kan tidak mungkin. Makanya kemudian dalam hubungan sosial kita katakan mereka non-Muslim. Di Arab sana kan juga gitu, di Arab Saudi misalnya tidak ada namanya 'jalan untuk orang kafir'(torikun lil kafir), yang ada jalan untuk selain muslim.

Non-Muslim dalam Negara Kesatuan Republik Indonesia (NKRI) tidak memenuhi syarat istilah-istilah kafir yang disebutkan dalam kitab-kitab fiqih. Indonesia bukanlah Negara Islam sehingga istilah-istilah tersebut tidak sesuai jika untuk menyebutkan non-Islam yang ada di Indonesia. Pada tahun 1953 diputuskan bahwa Status NKRI adalah Dârul Islam atau Dârus Salam dan bukan Dâulah Islâmiyah. Dasarnya adalah kitab Tubfatul Muntaj Syarah Minhaj Jilid 9 bahwa Dârul Islam adalah "Negara yang di dalamnya didiami mayoritas Muslimin). NonMuslim yang tinggal di Indonesia adalah non-Muslim yang bebas sama dengan umat Muslim di Indonesia, mereka bukan kafir yang mengikat perjanjian dengan negara dan mereka juga tidak memerangi umat Muslim seperti halnya kâfir harbi. Maka istilah-istilah kafir yang telah diuraikan diatas tidak sesuai jika untuk menyebut non-Muslim yang ada di Indonesia. Hal itulah yang kemudian membuat NUmengganti sebutan kafir menjadi non-Muslim.

Istilah yang ditetapkan untuk menyebut non-Muslim dalam konteks sosial adalah Muwathinun yang artinya warga negara. Dirumuskannya istilah tersebut adalah sebagai kontra narasi paham keagamaan terhadap doktrin takfiri yaitu pengkafirkan yang berbeda, tidak hanya non-Muslim tetapi juga kepada sesama kelompok muslim yang berbeda pandangan dan afiliasi keagamaan. Akan berbahaya jika ada umat Muslim yang suka menyebut kafir kepada orang lain yang berbeda dengannya, baik beda agama maupun beda paham keagamaan. Tidak sedikit umat Muslim saat ini yang telah terpengaruh dakwah berpaham takfiri baik melalui ceramah para mubaligh, da'i maupun ustadz. 
Hasil keputusan MunasAlim Ulama yang diadakan oleh forum Bahtsul Masâil alMaudlu'iyyah selanjutnya dibacakan oleh ketua umum PBNU Said Aqil Siraj pada saat penutupanMunas Alim Ulama dan Konbes NU yang berlangsung di Pondok pesantren Miftahul Huda Al-Azhar, Citangkola, Banjar, Jawa Barat pada Jum’at 1 Maret 2019.

"Dalam Sistem kewarganegaraan pada suatu negara bangsa, dalam bahasa arabnya Muwatonah tidak dikenal istilah kafir. Maka, setiap warga negara memiliki kedudukan dan hak yang sama dimata konstitusi. Istilah kafir berlaku ketika Nabi Mubammad di Mekkah tapi ketika Nabi Muhammad hijrah ke Kota Madinah tidak ada istilah kafir untuk warga negara Madinah yang non-Muslim. Ada tiga suku non-Muslim: suku Bani Qoinuqo, Bani Quraizah, dan Bani Nadir disebut non-Muslim, tidak disebut kafir. Ini harus kita jelaskan secara ilmiah, ya gapapa saya sendiri sering dikafirkan orang".

Adapun hasil keputusan Munas Alim Ulama ini belum final dan akan dibicarakan lagi dalam pertemuan internal-internal Syuriah PBNU. Jika hasil keputusannya sudah final maka selanjutnya akan menjadi Abkamul Fuqoha (kumpulan fatwa-fatwa Nahdlatul Ulama).

\section{Sikap PWNU Sumatera Utara Tentang Penggantian Istilah Kafir}

Pengurus Wilayah Nahdlatul Ulama Sumatera Utara (PWNU Sumut) turut menghadiri pertemuan Munas Alim Ulama dan Konbes NUyang dilaksanakan di Pondok Pesantren Miftahul Huda. Perwakilan dari PWNU yang hadir adalah Prof. Dr. KH Saidurrahman (Wakil Rois), Dr. Husni Ritonga (A'wan), Drs. H. Adlin Damanik (Wakil Ketua), Drs. H. Mhd Hatta Siregar (Sekretaris), dan KH. Akhyar Nasution (Ketua Ikatan Alumni al Syam Sumut dan Rois Syuriah PCNU periode 2013 s/d 2018).

Setelah pelaksanaan Munas Alim Ulama dan Konbes NUdi Jawa Barat selesai, 4 Maret 2019 PWNU Sumatera Utara menggelar pertemuandigedung Kantor PWNU Sumatera Utara di Jl. Sei Batang hari Medan. Pertemuan tersebut dihadiri oleh gabungan unsur Syuriah dan Tanfidziyah diantaranya Dr. KH. Abdul Hamid Ritonga (Wakil Rois), KH Hamdan Yazid (Wakil Rois), Al-Faqyr H. Abrar M Dawud (Katib), Muallim Syafii Umar (Wakil Katib), H. Abdullah Affaz (Wakil Katib), H. OK Zulkifli (Wakil Ketua), Prof. Hasratuddin Siregar (Wakil Ketua) dan beberapa orang lainnya dari unsur badan otonom dan lembaga Nahdlatul Ulama (NU). Dalam pertemuan tersebut membahas terkaithasil dari Munas NU.

Abdul Hamid (2019) mengatakan inti pokoknya, kita dengarkan dulu kronologis adanya hasil munas ini. Kita memerlukan ketenangan, jangan tegesa-gesa di tengah hiruk pikuk hinaan dan celaan kepada NU. Orang sudah mabuk, apapun kata NU sudah dianggap sesat, melawan orang mabuk berarti kita tidak sehat. NU sangat paham pesan al-Qur'an, Hadis dan ijma’ Ulama, sehingga tidak benar NU mengganti terminologi kafirsebagaimana yang ada di 
dalam al-Qur'an. Secara i'tiqad terminologi kafir diyakini oleh Nahdliyin tanpa ragu sedikitpun, namun dalam wilayah hubungan sosial Rasulullah mengajarkan akhlak al-karimah.

Menurut Hatta Siregar (2019) setelah hasil keputusan MUNAS dibacakan yaitu mengenai kafir-non-Muslim, dalam hubungan sosial sehari-hari maupun berbangsa dan bernegara, muncullah pihak-phak yang sengaja membenturkan NU dengan masyarakat dan umat Islam, bahwa seolah-olah NU menolak istilah kafirdalam al-Qur'an dan disebut ingin mengamandemen al-Qur'an.

Dr KH. KH Hamdan Yazid menegaskan bahwa hasil Munas NU di Kota Banjar tahun 2019 masih akan terus berlanjut dibahas oleh para alim ulama dan intelektual NU hingga saatnya nanti dikodifikasi dalam bentuk buku berjudul 'Abkam al-Fuqaha Nabdlatul Ulama. Sebenarnya penyampaian rumusan hasil Munas NU ini kurang tepat karena masih dalam situasi tahun politik pemilu, sehingga gagasan tasamubNU ini disalahpahami dan dibawabawa kearah politik untuk menyudutkan kelompok yang berbeda pilihan politiknya.

Forum pertemuan PWNU Sumut akhirnya menyerukan agar umat Islam Indonesia tidak terprovokasi atas stigma, plintiran, editan dan kesimpulan yang menyudutkan yang dibuat oleh kelompok yang tidak bertanggung jawab terhadap hasil Munas NU tersebut.

\section{Pengertian Kafir Menurut FUI}

Menurut Indra Suheri secara bahasa kafir berasal dari kata كفر- يكفر yang berarti menutup. Jika diartikan hanya sampai makna etimologi saja, tentu pengertian tersebut masih rancu dan belum jelas apa yang dimaksud dengan menutup. Maka untuk menjelaskannya kemudian dilanjutkan pengertian dari segi terminologi, yakni menutup diri dari ajaran Islam.

Pengertian kafir yang paling umum dan sering dipakai dalam buku akidah adalah "menolak kebenaran dari Allah SWT yang disampaikan oleh Rasul-Nya" atau secara singkat kafir adalah "kebalikan dari iman". Orang kafir adalah mereka yang menolak, menentang, mendustakan, mengingkari, dan bahkan anti-kebenaran. Dari segi akidah, kafir berarti "kehilangan iman", yang berarti pula "kehilangan sesuatu yang paling berharga dalam diri manusia"(Nina : 37). Firman Allah SWT dalam Surah An-Nahl ayat 55 :

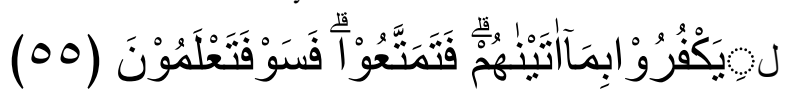

Artinya: "Biarlah mereka mengingkari nikmat yang telah kami berikan kepada mereka; maka bersenang-senanglah kamu. Kelak kamu mengetaui (akibatnya)". 


\section{Jenis Kafir Menurut FUI}

Forum Umat Islam (FUI) membagi kata kafir kedalam dua segi yaitu pembagian kafir dari segi Tauhid dan Fiqih. Dari segi tauhid kafir terbagi kepada dua golongan, yaitu Kâfir Harbi dan Kâfir Dzimmi.

\section{Kâfir Drimmi (كافر ذمي)}

Kâfir Drimmi adalah golongan non Islam yang tidak berbahaya dan tidak mengancam keselamatan umat Islam. mereka adalah golongan kafir yang mengikat perjanjian dengan umat Islam untuk tidak saling mengadakan permusuhan.

2. Kâfir Harbi(كافر هربي)

Kâfir Harbi adalah golongan non Islam yang memang memusuhi bahkan memerangi umat Islam. Mereka adalah golongan kafir yang senantiasa merasa bermusuhan dengan Islam, mereka adalah orang-orang yang setiap saat menaruh kebencian terhadap Islam (Rivai, 2012 : 312). Firman Allah SWT dalam al-Qur'an surah Al-Baqarah ayat 217:

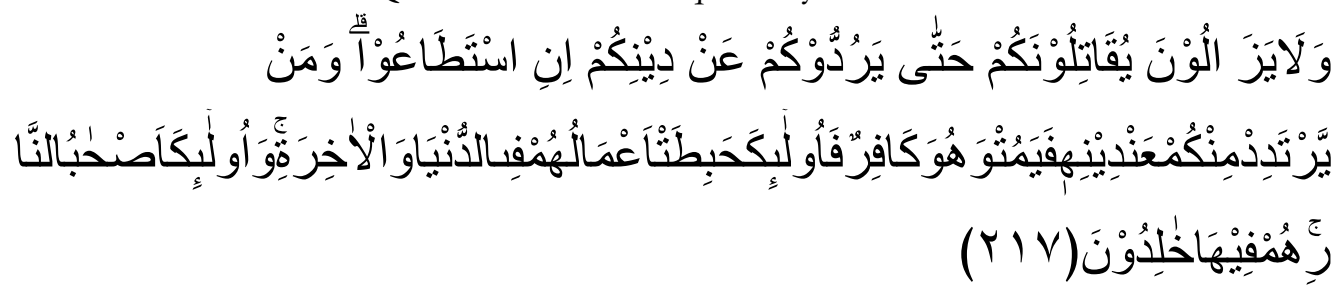

Artinya: "Mereka tidak akan berhenti memerangi kamu sampai kamu murtad (keluar) dari agamamu, jika mereka sanggup. Barang siapa murtad diantara kamu dari agamanya, lalu dia mati dalam kekeafirannya, maka mereka itu sia-sia amalnya di dunia dan di akbirat, dan mereka itulah penghuni neraka, mereka kekal di dalamnya".

Sedangkan dari segi fiqih kafir terbagi kepada Kâfir Takjïb dan Kâfir I'rad.

1. Kâfir Takdzib(كافر تكذب)

Takjib berasal dari kata يكذب - يكنبyang artinya mendustakan. Kafir Takdzil berarti kafir pendusta, yaitu non Islam yang mendusatakan dan mengingkari kebenaran Islam, mengingkari keesaan Allah sebagai satu-satu nya Tuhan yang berhak disembah, dan mengingkari ajaran Islam yang dibawa oleh rasul-rasul Nya, khususnya Rasulullah Muhammad Saw.

Inilah golongan non Islam yang berbeda keyakinan dengan Islam, yaitu mereka yang beragama diluar Islam seperti Kristen, Hindu, Buddha dan agama lainnya selain Islam. Kafir takdzib yang termasuk didalamnya baik kafir harbi maupun dzimmi.

\section{Kâfir I'rad (كافر اعرد)}

I'rad artinya berpaling dari syariat Islam. Kâfir I'rad adalah golongan kafir yang secara lahiriah nampak beriman tetapi batinnya mengingkari Tuhan dan mereka itulah yang disebut 
orang munafik. Jadi istilah kafir bukan hanya untuk melabeli orang non Islam saja tetapi umat Islam yang munafik pun juga disebut kafir. Jelas sekali di dalam al-Qur'an surah At-taubah ayat 84 :

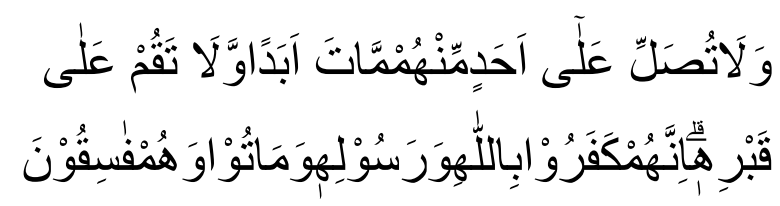

Artinya: "Dan janganlah engkau (Muhammad) melaksanakan salat untuk seseorang yang mati di antara mereka (orang-orang munafik), selama-lamanya dan janganlah engkau berdiri (mendoakan) di atas kuburnya. Sesungguhnya mereka ingkar kepada Allab dan Rasulnya dan mereka mati dalam keadaan fasik".

\section{Argumentasi FUI SUMUT Dalam Menilai Hasil Putusan Munas NU}

Mengenai pernyataan NU melalui Munas NU, bahwa kata kafir diperhalus menjadi non-Muslim. Tentu pernyataan tersebut sudah kontra produktif jika berdasarkan makna etimologi dan terminologi kafir itu sendiri. Tidak bisa diterima dengan hukum akal jika kata kafir diganti dengan non-Muslim, sebab yang disebut kafir tidak hanya orang non-Muslim saja, orang Islam sendiri pun yaitu orang munafik juga Allah sebut kafir. Orang munafik secara administrasi ktpnya Islam, orang munafik juga solat, puasa, zakat, berangkat haji namun yang namanya munafik mereka diibaratkan bermuka dua. Selain orang munafik, hukum yang berlaku saat ini juga dikafirkan Allah (Suheri, 2019). Firman Allah dalam al-Qur'an surah AlMaidah 44:

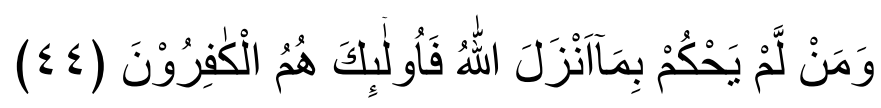

Artinya: "Barang siapa yang berbukum yang tidak sesuai dengan yang diturunkan Allah maka mereka telah kafir".

Seperti hukum yang berlaku di Indonesia saat ini, hukum yang mengadopsi hukum Belanda sehingga sampai detik ini sulit untuk diamandemen. Dapat dinyatakan bahwa hukum yang berlaku saat ini adalah hukum buatan manusia, maka hukum yang berlaku saat ini juga dikafirkan Allah sebab telah berhukum kepada hukum yang bukan berasal dari Allah. Jadi jangan anggap kata kafir itu kasar, intoleran, kata tidak bersahabat, anti kebhinekaan. Semua itu hanyalah tudingan-tudingan fitnah yang disampaikan oleh orang-orang kafir non-Muslim dan kafir golongan munafik seperti kelompok Islam liberal, sekuler, kelompok syiah, termasuk kelompok wahabi.

Orang non-Muslim yang ada di Indonesia mayoritas tergolong kepada kâfir drimmi, hal ini terlihat dilapisan masyarakat di tengah kebhinekaan antara suku, ras dan golongan. Mereka sudah mulai bisa meresapi nilai-nilai pancasila bahwa prinsip toleransi dalam kebhinekaan memang harus dikedepankan. Tetapi selain kâfir dżimmi ada juga kâfir harbi, 
terbukti dengan adanya perilaku-perilaku intoleran seperti di Papua ketika memperjuangkan masyarakatnya melalui lembaga politik di DPRD yang ingin memperjuangkan larangan membangun masjid dan larangan adzan dan juga ingin menjadikan Papua sebagai kota Injil. Begitu juga dengan Poso dan Ambon, mereka adalah kâfir harbi yang memang memusuhi umat Islam, menabuh genderang perang dan mereka tergolong orang-orang kafir yang radikal sebagaimana isyarat al-Qur'an surah Al-Baqarah 217 (Suheri , 2019).

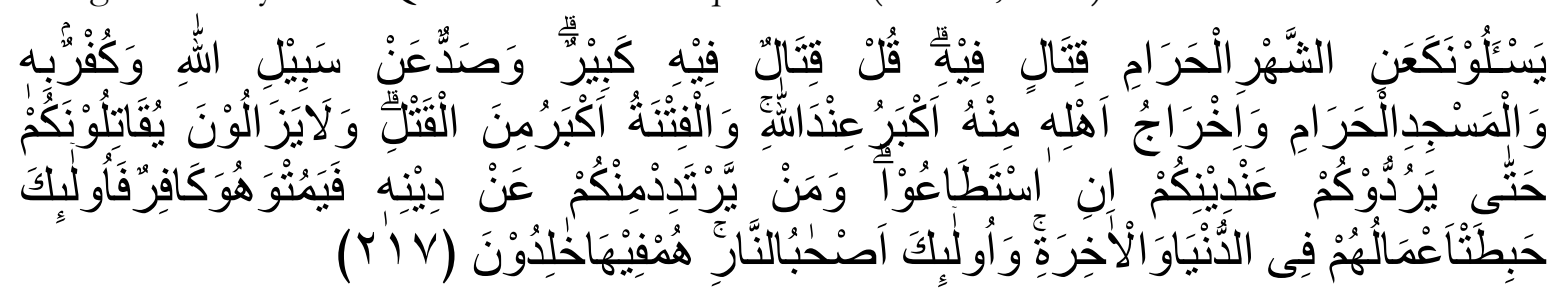

Artinya: "Mereka bertanya kepadamu (Muhammad) tentang berperang pada bulan haram. Katakanlah, "Berperang dalam bulan itu adalah (dosa) besar. Tetapi menghalangi (orang) dari jalan Allah, ingkar kepada-Nya, (menghalangi orang masuk) Masjidilharam, dan mengusir penduduk dari sekitarnya, lebih besar (dosanya) dalam pandangan Allab. Sedangkan fitnah lebih kejam daripada pembunuban. Mereka tidak akan berhenti memerangi kamu sampai kamu murtad (keluar) dari agamamu, jika mereka sanggup. Barangsiapa murtad di antara kamu dari agamanya, lalu dia mati dalam kekafiran, maka mereka itu sia-sia amalnya di dunia dan di akbirat, dan mereka itulah penghuni neraka, mereka kekal di dalamnya" (Depag RI : 34)

Islam adalah agama yang universal yang berlaku untuk seluruh alam sebagaimana firman Allah dalam al-Qur'an surah Al- Anbiya ayat 107:

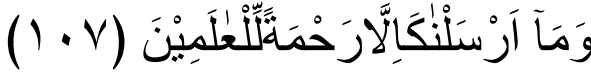

Artinya: "Dan tidaklah kami mengutus kamu, melainkan untuk (menjadi) rahmat bagi semesta alam".

Ayat tersebut menegaskan bahwa Ajaran Islam tidak bergantung pada waktu dan tempat. Waktu dalam arti sejak zaman Rasulullah Saw, sekarang, dan sampai hari kiamat, Islam itu tetap sama dan Islam sangat bisa mengikuti perkembangan peradaban manusia. Kemudian Islam tidak tergantung tempat artinya di manapun tempatnya di bumi Allah, di negara sekalian alam di Mesir, India, Pakistan, Fhiliphina, Indonesia, Afrika, Vietnam, Amerika maupun di negara-negara yang lain, Islam sesungguhnya adalah agama yang bisa dipakai di seluruh tempat tanpa perlu menyesuaikan dengan kultur bangsa atau masyarakat setempat. Inilah barangkali yang diperjuangkan dan dipelopori oleh kelompok Islam Nusantara yang merupakan buah dari pemikiran NUitu sendiri. Mereka mencoba memperjuangkan Islam Nusantara karena ingin menyesuaikan ajaran Islam dengan budaya kultur sosial masyarakat Indonesia dan ini tidak dikenal dalam ajaran Islam (Suheri, 2019). Jika Islam dikotak-kotakan seperti itu maka tidak akan ada lagi wujud Islam sebagai Ummatan Wabidah (umat yang satu). 
Jika NU mengatakan bahwa istilah kafir tidak sesuai untuk mengistilahkan nonMuslim yang di Indonesia, maka itu sangat bertentangan dengan ajaran Islam yang berlaku secara umum dan menyeluruh. Amat keliru jika ada yang mengkotak-kotakan pemahaman Islam dari segi tempat dan teritorial.

Sikap FUI selaku Ormas Islam yang berbasis dakwah amar ma'ruf nabi munkar sangat tidak bisa menerima pernyataan hasil Munas Alim ulama NU yang ingin mengganti kata kafir menjadi non-Muslim. Yang paling anehnya, ketika kata kafir diganti menjadi non-Muslim maka bagaimana nanti penyesuaiannya dengan surah Al-kafirun, namanya saja sudah surah orang-orang kafir jadi bagaimana kalau harus diganti dengan non-Muslim (Suheri, 2019).

Silahkan saja jika NU merekomendasikan untuk menyebut orang-orang di luar Islam dengan sebutan non-Muslim dalam hal administrasi Negara dan tetap mengangap kafir dalam hal aqidah. Tetapi FUI menilai bahwa itu hanyalah sebuah pernyataan alasan yang diadaadakan. FUI tetap membantah pernyataan itu karena menurut mereka, ada muatan politis yang terkandung dibalik pernyataan tersebut. Melihat kondisi politik Indonesia saat ini, ketika Jokowi dan Ma'ruf Amin naik sebagai Presiden dan Wakil Presiden, Ma'ruf Amin yang dengan kondisinya terlihat telah lanjut usia, ketika seseorang sudah lansia maka bisa saja sakit-sakitan kemudian ketika beliau sakit yang berkepanjangan, beliau akan digantikan oleh orang lain, dalam hal ini FUI melihat antara Haritano atau Ahok yang nanti akan menggantikan posisi Ma'ruf Amin sebagai Wakil Presiden. Jelas bahwa kedua orang ini adalah non-Muslim. Yang menjadi kekhawatiran adalah ketika pemilihan Presiden mendatang yaitu tahun 2024, ketika Ahok atau Haritanu telah mendapatkan posisi yang aman yaitu sebagai wakil presiden. Ketika mereka ingin menjabat lagi sebagai presiden dan wakil presiden, dengan adanya pemahaman bahwa orang kafir tidak lagi disebut kafir, tetapi disebut non-Muslim, masyarakat akan terbiasa dengan istilah tersebut. Kemudian ini akan menjadi dahil bagi dibolehkannya memilih Ahok / Haritanu sebab didalam al-Qur'an yang diharamkan adalah memilih pemimpin kafir bukan non-Muslim.

\section{Analisis Perbandingan Konsep Kafir Menurut NU dan FUI Sumatera Utara}

Islam adalah agama yang khas dan berbeda dengan agama yang lain. Salah satu kekhasan Islam adalah mengenai pengaturan Istilah. Islam menggunakan istilah-istilah dengan makna tertentu untuk membedakan suatu perkara dengan perkara lainnya agar jelas perbedaannya. Untuk membedakan pemeluk agama yang dibawa oleh nabi Muhammad Saw dengan pemeluk agama lain digunakanlah istilah Islam dan kufur, Muslim dan kafir.

Orang yang tidak percaya kepada Allah SWT dan Rasul Nya disebut kafir. Secara kebahasaan, al-kâfir berarti "menutupi sesuatu”, menyembunyikan kebaikan yang diterima", 
atau "tidak berterima kasih".Secara syar'i kafir adalah siapa saja yang tidak mengimani Allah dan Nabi Muhammad Sawatau siapa saja yang mengingkari ajaran apapun yang diketahui secara pasti berasal dari Islam, atau yang merendahkan kedudukan Allah dan risalah Islam (Rawwas, 2019).

Kafir menurut al-Qur'an terbagi kepada kâfir kitabi dan kâfir musyrik.Dikatakan kâfir kitabi sebabmereka adalah golongan kafir yang memiliki kitab suci yang berasal dari Allah dan agama mereka tergolong kepada agama samawi yaitu Yahudi dan Nasrani. Pada dasarnya mereka (Yahudi dan Nasrani) mengimani beberapa kepercayaan pokok yang dianut Islam, namun kepercayaan mereka tidak utuh, cacat sebab mereka tidak mengimani kerasulan Muhammad Saw dan ajaran Islam yang dibawa nya. Kemudian golongan selanjutnya yaitu kâfir musyrik, kâfir musyrik adalah mereka yang menganut agama ardhi seperti Hindu, Buddha, Konghucu, dan Majusi. Dikatakan kâfir musyrik sebab agama mereka adalah agama karangan atau buatan manusia dan bukan berasal dari Allah. Firman Allah dalam Surah Al-Bayyinah ayat $6:$

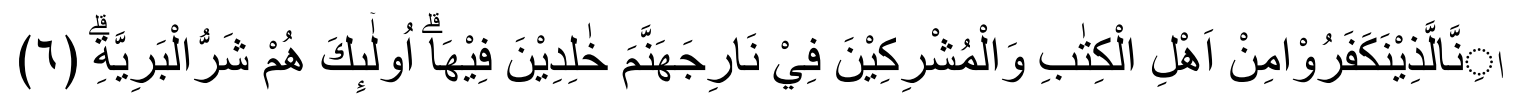

Artinya: "Sungguh orang-orang kafir dari kalangan Ablul Kitab (Yahudi dan Nasrani) dan kaum musyrik (kaum paganis) pasti berada di Neraka Jahanam. Mereka kekal di dalamnya. Mereka adalah seburuk-buruknya makbluk".

Istilah kafir sebenarnya bukanlah istilah yang baru dalam Islam. Jauh sebelum saat ini istilah kafir juga sudah lebih dulu Rasulullah gunakan Sebagai kepala Negara Islam di Madinah. Pada Pasal ke-14 Piagam Madinah jelas dinyatakan:

Pasal 14: Seorang Mukmin tidak boleh membunuh Mukmin lainnya lantaran membunuh orang kafir. Tidak boleh pula orang Mukmin membantu orang kafir untuk (membunuh) orang Mukmin (Hisyam, $2000: 455)$.

Dengan ini, pendapat yang menyatakan kata kafir tidak pernah digunakan Rasulullah untuk menyebut orang kafir yang ada di Madinah, dapat dibantah, karena Rasulullah menyebut orang-orang non Islam dengan sebutan kafir.

NUsebagai organisasi Islam terbesar di Indonesia, sepertinya memiliki satu pemikiran, artinya satu komando dengan pemimpinan mereka. Penggantian istilah kafir menjadi non-Muslim adalah hasil dariMunas NU pada Komisi Babtsul Masâil Maudhuliyyah di Banjar Jawa Barat, dan PWNU Sumut ketika diwawancarai mengenai putusan tersebut, menyatakan sepakat dan sepemikiran dengan hasil putusan Alim Ulama NU.

Martin Lukito Seorang Pendeta dan Dosen Sekolah Tinggi Teologi Jakarta yang melihat bahwa usulan NU tersebut merupakan sebuah langkah yang luar biasa dan 
momentumnya pun sangat tepat karena dapat menjalin kembali tali sosial antarumat beragama yang sempat dirasakan rusak setelah pemilihan Gubernur Jakarta 2017. Sebab pasca pemilihan Gubernur Jakarta, orang Kristen sering dipojokkan sebagai minoritas kafir. Ada perkembangan yang kurang baik dengan istilah itu dan ada stigma negatif.

Hal senada disampaikan oleh wakil ketua advokasi hak asasi manuia; Bonar Tigor Naipospos bahwa rekomendasi NU tersebut merupakan terobosan signifikan untuk memperkuat toleransi dan kesetaraan berdasarkan Pancasila dan konstitusi Negara.

Gustav wakil sekretasi PGW-SU menyatakan setiap agama menggunakan istilah kafir atau istilah lain untuk menyebut orang yang diluar agamanya. Dalam kekristenan, kafir berarti mereka yang tidak menyembah Tuhan yang disembah oleh umat Kristen. Namun dalam Alkitab kata kafir jarang dipergunakan dan yang biasa digunakan dalam Al-kitab adalah penyembah berhala. Kalau merujuk kepada kata kafir memang itu bisa menyakitkan orang yang berbeda agamanya, maka kata tersebut harus dihindari. Orang Kristen akan lebih nyaman disebut dengan non-Muslim atau Kristen. Dan apa yang dilakukan oleh NU menjadi sebuah terobosan baru dalam konteks kebangsaan.

FUI sebagai gerakan dakwah amar ma'ruf nahi mungkar sangat menentang pernyataan NU yang ingin mengganti istilah kafir menjadi non-Muslim. Meskipun FUI adalah ormas Islam yang baru terbentuk, dan sepak terjang dakwahnya juga belum selama NU, namun dalam menyampaikan amar ma'ruf nabi mungkar, menyuarakan kebenaran, mengkritisi, menyampaikan pendapat tidak harus orang yang setara dengan orang yang mau dikritisi. Bahkan pada masa pemerintahan Umar bin Khattab, beliau adalah khalifah yang sangat senang dikritik oleh rakyatnya. Artinya FUI sebagai gerakan yang baru juga boleh mengkritisi dan memberikan pandangan yang berbeda kepada NUmengenai istilah kafir.

Pandangan NUdanFUI Sumatera Utara dalam mendefenisikan istilah kafir masih sama. Bahwa kafir adalah orang Yang menutup diri dari ajaran Islam. Hanya saja FUI) tidak sepakat jika kata kafir diganti menjadi non-Muslim meskipun hanya dalam konteks kebangsaan.

Penulis sependapat dengan pemikiran Forum Umat Islam (FUI) bahwa tidak boleh mengubah istilah yang memang sudah ada dalam al-Qur'an. Setiap hukum dan istilah yang diturunkan oleh Allah SWT tetap berlaku sampai hari Kiamat tanpa harus menyesuaikan ajaran Islam dengan kondisi teritorialnya. Surah Al-Kafirun adalah surah yang diturunkan di Makkah namun surah ini tetap berlaku di Madinah bahkan sampai hari kiamat.

Penulis menilai bahwa sebenarnya istilah kafir ini tidak perlu dipermasalahkan sebab dalam konteks sosial, dalam dialog dengan non-Muslim, umat Islam paham bahwa tidak sopan 
menyebut orang-orang di luar Islam dengan sebutan kafir dan istilah kafir juga tidak ada digunakan dalam perundang-undangan yang berlaku.

Namun apabila mereka (non Islam) tersinggung ketika disebut kafir, lantas bagaimana dengan istilah yang mereka gunakan untuk menyebut orang yang diluar agama mereka. Dalam ajaran Buddha, Non Budhis disebut Abrahmacariyavasa, dalam ajaran Yahudi, orang diluar Yahudi disebut Ghoyim yang artinya lebih rendah dari binatang. Dalam ajaran Kristen, Non Kristen disebut Domba yang tersesat. Dan dalam ajaran Islam, non-Muslim disebut kafir.

Jika penyebutan kafir kepada non-Muslim adalah sebuah bentuk diskriminasi dan kekerasan teologis, lantas bagaimana dengan tudingan wahabi, radikal, garis keras, fundamentalisme, ekstrimis, teroris dan tudingan senada yang juga termasuk kedalam bentuk diskriminasi kepada umat Islam.

Seorang tokoh perbandingan agama; Dr. Zakir naik pernah berkata bahwa jika seorang non-Muslim merasa terhina bila disebut kafir, itu berarti dia belum paham dengan Islam. Dia harus mencari sumber yang tepat untuk memahami Islam dan terminologi Islam. dengan memahaminya, ia bukan saja tidak akan merasa terhina, tetapi justru menghargai Islam dalam perspektif yang lebih tepat.

Jika dicermati, banyak istilah-istilah lain dalam Islam yang juga diperhalus penyebutannya agar terdengar bagus dan memikat.Bukan hanya istilah kafir yang diganti menjadi non-Muslim, namun istilah lain seperti riba yang pelakunya diancam kekal di neraka, diganti istilahnya dengan bunga, atau dalam bahasa arab fa'idah. Istilah Pezina diganti dengan istilah psk (pekerja seks komersial), zina disebut kebebasan dan istilah-istiah lain semacamnya.

\section{Penutup}

Dari penjelasan diatas, dapat disimpulkan bahwa:

1. Menurut NU Sumut, kafir berarti selain orang Muslim. Kafir terbagi 4 golongan, yaitu kâfir Harbi, kâfir Drimmi, Kâfir Mu'abad dan kâfir Musta'min. Dan kesemua itu adalah jenis-jenis kafir yang terdapat dalam kitab-kitab fiqih namun istilah-istilah tersebut tidak sesuai jika untuk mengistilahkan orang-orang kafir yang ada di Indonesia, maka non Islam yang ada di Indonesia tidak disebut kafir tetapi nonMuslim.

2. Menurut NU jika dalam konteks bernegara, mereka umat Islam, Kristen, Hindu, Buddha, Konghucu mempunyai hak dan kewajiban yang sama dimata konstitusi, sama-sama berjuang melawan penjajah dan sama-sama hidup bebas di dalam Negara Kesatuaan Republik Indonesia, maka dalam bernegara mereka disebut warga negara (muwâthinun), namun dalam hal aqidah mereka tetaplah kafir. 
3. Rekomendasi NU tersebut merupakan bentuk dari kontra narasi terhadap paham takfiri (saling kafir mengkafirkan antar sesama uamt Islam yang berbeda paham atau afiliasi keagamaannya)

4. Hasil keputusan Munas NU belum final dan akan dibicarakan lagi dalam pertemuan internal-internal Syuriah PBNU. Jika keputusannya sudah final maka selanjutnya akan dimasukkan kedalam Abkamul Fuqoba (Kumpulan fatwa-fatwa NU).

5. PWNU Sumut menyerukan agar umat Islam tidak terprovokasi atas stigma, plintiran, editan dan kesimpulan yang dibuat oleh kelompok yang tidak bertanggung jawab untuk menyudutkan NU.

6. Menurut FUI Sumut, secara bahasa kafir berasal dari kata kâfara-yakfuru yang berarti menutup. Dari segi istilah yang dimaksud menutup adalah menutup diri dari ajaran Islam. Dalam ajaran Islam kafir terbagi kepada kafir dari segi tauhid dan kafir dari segi fiqih. Dari segi tauhid kafir terbagi kepada kâfir harbi dan kâfir džimmi. Sementara dari segi fiqih kafir terbagi menjadi kâfir takjïb dan kâfir i'rad.

7. FUI tidak sependapat jika kafir diganti menjadi non-Muslim sebab istilah kafir bukan saja digunakan untuk menyebut orang yang diluar agama Islam, orang Islam yang munafik pun dalamal-Qur'an disebut kafir. Jadi istilah kafir bukanlah istilah yang kasar. Islam adalah agama yang bisa dipakai diseluruh tempat tanpa perlu menyesuaikan dengan kultur bangsa atau masyarakat setempat sehingga ajaran Islam tetap sesuai dimana dan kapan saja. Begitu juga dalam penggunaan istilah kafir tidak bisa dikatakaan bahwa istilah itu tidak sesuai untuk menyebut non-Muslim di Indonesia, sebab ajaran Islam berlaku sejak zaman Rasulullah, saat ini dan sampai hari kiamat.

8. PWNU Sumut menyampaikan bahwa jika FUI tidak sependapat dengan pemikiran mereka, maka NU membuka diri untuk mengajak berdialog dalam forum ilmiah agar masing-masing memberikan argumentasinya. FUI menyambut baik ajakan tersebut untuk bersama-sama duduk dalam sebuah forum ilmiah dengan syarat adanya penengah atau moderator yang bisa menengahi jalannya forum tersebut, tentunya penengahnya bukanlah orang yang berafiliasi di NU dan bukan juga di FUI.

\section{Daftar Pustaka}

Abdurrahman, Hafidz. Islam politik \& Spiritual. Bogor: Al-Azhar Press, 2015.

Departemen Agama RI.Al-Qur'an dan Terjemah.Bandung: CV. Diponegoro, 2008.

Harahap, Syahrin. dan Bakti, Hasan.Ensiklopedia Aqidah Islam. Jakarta: Prenada Media Group, 2009. 
Hisyam, Ibnu.Sirah an-Nabi saw. Jidil I, terj. Fadhli Bahri. Bekasi: Darul Falah, 2000.

Jirhanuddin.Perbandingan Agama.Yogyakarta: Pusataka Pelajar, 2010.

Mardalis. Metodologi Penelitian: Suatu Pendekatan Masalah. Jakarta: Bumi Aksara, 2008.

M. Armando, Nina. et. al. Ensiklopedia Islam, Jakarta: Ichtiar Baru Van Hoeve, 2005.

Media Politik dan Dakwah: Al-Wa’ie, Perang Istilah Kafir. Edisi April 2019.

Nafi, M. Zidni.Menjadi Islam Menjadi Indonesia.Jakarta:Elex Media Komputindo, 2018.

Nasrulloh.Hadits-Hadits Anti Perempuan: Kajian Living Sunnab Perspektif Mubammadiyah, NU, \& HTI.Malang: UIN MALIKI PRESS, 2015

Nasution, Harun. Teologi Islam. Jakarta: UI-Press, 1986.

Nata, Abuddin. Metodologi Studi Islam. Jakarta: Raja Grafindo Persada, 2016

Noor, Juliansyah. Metodologi Penelitian: Skripsi, Tesis, Disertasi, dan Karya Ilmiah. Jakarta: Kencana Prenada Media Group, 2012.

Nazir, Moh. Metode Penelitian. Bogor Selatan: Ghalia, 2005.

Purba, Hadis.et. al.Theologi Islam.Medan: Perdana Publishing, 2018.

Reni, Nuryantidan Suryanto, Peno.Penelitian Sebuah Pengantar.Yogyakarta: UKM Penelitian UNY, 2006.

Rivai, Ahmad.et. al, Ensiklopedi Praktis Kerukunan Umat Beragama.Medan: Perdana Publishing, 2012.

Sugiyono. Metode Penelitian Pendidikan: Pendekatan Kualitatif, Kuantitatif dan R\&D. Bandung: Alfabeta, 2010.

Syamsuddin Ramadhan, Fathiy. Islam Menjawab!. Cibubur: Budira, 2010.

Van Bruinessn, Marvin. NU,Tradisi, Relasi-Relasi Kuasa, Pencarian Wacana Baru. Yogyakarta: LKIS, 1994

Bapak Abror M. Dawud Faza, (Katib PWNU Sumatera Utara)

Ustadz Indra Suheri (Ketua Umum FUI Sumut),

Bapak Bima Gustav Saragih (Wakil Sekretaris Umum PGI WSU)

https://www.benarnews.org

https://www.cnnindonesia.com

https://news.detik.com

https://pwnusumut.or.id/sejarah/

https://regional.kompas.com http://www.nu.or.id 